\title{
Keep Calm and Lead by Example: Healthy Lifestyles of Dietitians and Satisfaction with Life
}

\section{Grace-Farfaglia PM ${ }^{1,3 *}$, Pickett-Bernard $\mathrm{DL}^{2}$, Gorman $\mathrm{AW}^{3}$ and Dehpahlavan J²}

${ }^{1}$ University of Connecticut, Department of Nutritional Sciences, USA

${ }^{2}$ Life University, Department Nutrition, USA

${ }^{3}$ Rocky Mountain University of Health Professions, Health Science, USA

Corresponding Author: Patricia M Grace-Farfaglia, Adjunct Lecturer, University of Connecticut, Department of Nutritional Sciences, USA, Tel: 203-270-0097; E-mail: patricia.grace-farfaglia@uconn.edu

Received date: January 12, 2018; Accepted date: January 29, 2018; Published date: February 6, 2018

Citation: Grace-Farfaglia PM, Pickett-Bernard DL, Gorman AW, Dehpahlavan J (2018) Keep Calm and Lead by Example: Healthy Lifestyles of Dietitians and Satisfaction with Life. J Prev Med Vol.3 No.1:6.

Copyright: (C) 2018 Grace-Farfaglia PM, et al. This is an open-access article distributed under the terms of the Creative Commons Attribution License, which permits unrestricted use, distribution and reproduction in any medium, provided the original author and source are credited.

\section{Abstract}

Background: The goal of nutrition-focused preventive services is to impact health outcomes for the individuals receiving counselling and education. To date, there has been no comprehensive evaluation of personal lifestyles and satisfaction with life of Registered Dietitians Nutritionists.

Methods: The study aims were to evaluate the reliability of the English version of the Healthy Lifestyle and Personal Control Questionnaire (HLPCQ) and to determine their relationship to satisfaction with life in a random sample of US dietitians ( $n=493)$. The HLPCQ was administered online to US dietitians in October 2016 and resulted in a sevenfactor solution, and these dimensions were compared to dietitian's beliefs about health and nutrition to determine construct validity.

Findings: Cronbach's coefficients for the full scale were 0.824 , and seven subscales varied from 0.464 to 0.853 . Discriminant analysis was used to differentiate between participants' gender, health behaviors, and health philosophy on satisfaction with life. Health-related behaviors were positively and significantly associated with SWL. Conclusion: The health behaviors that predicted life satisfaction were routine physical activities, and socialemotional support behaviors. The identification of the key determinants influencing life satisfaction is essential for designing personal health interventions to improve lifespan wellness for allied health professionals.

Keywords: Health; Lifestyle; Dietetic practice; Satisfaction with life; Wellbeing

\section{Background}

The position of the Academy of Nutrition and Dietetics (AND) states that the goal of health promotion is the adoption of health-related lifestyle behaviors [1]. The main role of dietitians is to provide nutrition education and interventions which promote health across the lifespan and well-being. Yet, little has been published related to the role of personal wellness habits and practices of dietitians compared to that devoted to the health promoting lifestyles of other health professionals [2-8].

A recent study reported that less than half of Registered Dietitians surveyed met the guidelines for physical activity which could have a negative impact on the content of client lifestyle counseling [7]. Furthermore, clients themselves respond differently to recommendations from health professionals who appear physically fit $[9,10]$. The integrative perspective of health maintains that individuals are imbedded within a socioeconomic structure where behaviors are largely determined by choice, but may be influenced by an ideology embraced by the healthcare system and its practitioners.

According to the theory of planned behavior (TPB) an individual will assess his intention to adopt a new behavior based on personal behavioral, normative and control beliefs [11]. Thus, an individual's health philosophy reflects the normative beliefs of society as a whole, and its institutions. Studies utilizing the expectancy-value theory demonstrate that behavior is a function of the expectations of the individual and the value of the goal toward which one is working [12]. Furthermore, studies based on the Pender's Health Promotion model have shown that an individual's definition of health predicts the likelihood of engaging in health-promotion or health-protecting behaviors $[13,14]$. One of its propositions states that an individual will commit to engaging in behaviors if they believe that the goal is a valued benefit.

Health philosophy in the context of healthcare practice is the "actualization of inherent and acquired human potential through goal-directed behavior, competent self-care, and satisfying relationships with others, while adjustments are made as needed to maintain structural integrity and harmony with relevant environments" [15]. The Pender Health Promotion model serves as the framework for exploring whether a 
dietitian's lifestyle is defined by their personal view of health, and whether a health-promoting philosophy favors the desire for a high state of wellness [14]. Extending the Pender model, this study proposes that the ultimate impact of healthpromoting behaviors is the outcome of satisfaction with life.

The aim of this study was to explore the relationship between the health-related behaviors of the dietitian and life satisfaction, and the extent to which health philosophy drives a dietitian's health-promoting lifestyle. Understanding the health philosophy and motivates personal behaviors of health professionals who are engaged in health intervention is critical for health promotion planning and evaluation. Ultimately, the personal and professional practices of a health professional must support her ability to foster healthy lifestyles in others.

\section{Methods}

An exploratory study was performed using a cross-sectional online survey of 520 randomly selected Registered Dietitian Nutritionists within a sampling frame of 89,300 dietitians [16]. The inclusion criteria were having the registered dietitian nutritionist credential with the Commission on Dietetic Registration. Random selection increased the likelihood that a diverse range of dietetic practitioners would respond to the survey while reducing the potential for selection bias. The effect size of 0.50 was chosen for a medium to large importance of effect of health conception on lifestyle and professional practice $[17,18]$. Because this is also a correlational study, the minimum sample size to determine whether a correlation coefficient differs from zero is 139 [19]. The results of an outlier analysis reduced the sample size $(n=493)$ by $5 \%$.

Laffrey's Health Conception Scale (LHCS) scale, reduced version, was used to identify the personal definition of health or health philosophy [20]. Self-reported variables such licenses or certifications held and specific integrative therapies were included as measures of role identity and practice specialization. The health philosophy of registered dietitians was described in greater detail in our previous paper [21].

The Healthy Lifestyle and Personal Control Questionnaire (HLPCQ) measured personal lifestyle practices and the degree to which the individual feels empowered through their lifestyle and health choices [22]. The HLPCQ scale was designed to reflect daily activities in six dimensions: Dietary Healthy Choices, Dietary Harm Avoidance, Daily Routine, Organized Physical Exercise, and Social and Mental Balance.

This instrument was developed and validated against the perceived stress and health locus of control scales in a Greek convenience sample $(n=308)$, with the summary score being positively correlated with internal health locus of control $(r=0.10, p=0.003)$, perceived stress $(r=-0.42, p<0.001)$, sleep quality $(r=0.29,<0.001)$, and health assessment $(r=0.28$, $\mathrm{p}<0.001)$. This study validated the English version against a measure of an individual's personal philosophy of health, the satisfaction with life scale (SWLS) [23].
The SWLS questionnaire reflects the quality of an individual's life as a single underlying dimension on a scale ranging from strongly agree to strongly disagree. Studies report reliabilities in the range of Cronbach alpha 0.80 to 0.96 [24]. There is a tendency for results of this measure to be related to the individual's current situational context, although it has been demonstrated to be fairly stable overtime. In this study, the context was the respondent's global sense of well-being from lifestyle and career influences. In the event of recent life changes, such as widowhood or job loss, the stability of this measure could be threatened [25].

The measure for health philosophy was Lafferty's Health Conception Scale (LHCS), a scale that was originally developed and validated in a sample of nursing students to tap into clinical, functional, adaptive, and wellness aspects of the belief about the health construct, but was later reduced to two dimensions reflecting the belief in either health-promoting or healthprotecting behaviors in a sample of adolescents $[20,26,27]$.

The validity of the revised LHCS scale was confirmed in a study of white and blue collar workers, which reported Cronbach's alpha reliabilities of 0.83 overall and 0.89 for wellness and clinical health dimensions, respectively [20]. These results demonstrate that the LHCS instrument is internally consistent.

The theoretical model proposed is that belief in health as wellness, rather than pathology, motivates the dietitian to adopt healthy lifestyles and personal control behavioral orientation in their private life. Furthermore, satisfaction with life, a measure of subjective well-being, is the outcome of a convergence between health beliefs and daily practices.

\section{Results and Discussion}

An outlier analysis of the HLPCQ summarized index was performed using the outlier labeling technique. This method identified 27 out of 520 cases or $5.2 \%$ as outliers and were removed to allow the use of parametric methods. One of the aims of this study was to validate the English version of the HLPCQ.

The results of the principal component analysis of the 26 items with varimax rotation resulted in a 7-factor solution. Itemto-total correlations for each question correlated with the index score produced an overall Cronbach's alpha of 0.853 , and subscales varied from 0.464 to 0.845 . The average zero-order correlation between individual items was 0.236 (Table 1 and 2).

The resulting factor loadings had minor differences from the original sample of Greek participants [22]. Specifically, the Dietary Healthy Choices items were split into factors 3 and 4, with the later loading with Dietary Harm Avoidance and Social and Mental Balance items (Table 2). The latent themes that are reflected in these factors make theoretical sense within the context of the practice of dietetics. 
Table 1: Sociodemographic characteristics $(n=477)$.

\begin{tabular}{|c|c|c|}
\hline \multicolumn{3}{|c|}{ Characteristics (\%) } \\
\hline \multirow{2}{*}{ Gender } & Males & $16(3.4)$ \\
\hline & Females & $460(96.4)$ \\
\hline \multirow{7}{*}{ Years in Practice } & Less than one & $25(5.2)$ \\
\hline & 01-Apr & $96(20.1)$ \\
\hline & 05-Sep & $81(17.0)$ \\
\hline & Oct-14 & $48(10.1)$ \\
\hline & $15-24$ & $75(15.7)$ \\
\hline & $25-34$ & $98(20.5)$ \\
\hline & Greater than 35 & $54(11.3)$ \\
\hline \multirow{3}{*}{ Highest Degree } & Bachelor's & $208(43.6)$ \\
\hline & Masters & $240(5.5)$ \\
\hline & Doctorate & $26(5.5)$ \\
\hline
\end{tabular}

Table 2: Principal components analysis with varimax rotation of the HLPCQ scale $(n=493)$.

\begin{tabular}{|c|c|c|c|c|c|c|c|}
\hline \multirow[t]{2}{*}{ Item “How often..." } & \multicolumn{7}{|c|}{ Factor loadings } \\
\hline & 1 & 2 & 3 & 4 & 5 & 6 & 7 \\
\hline DR-Do you eat lunch at the same time each day & 0.786 & 0.069 & 0.008 & 0.033 & -0.047 & 0.036 & 0.100 \\
\hline DR-Do you eat dinner at the same time each day & 0.772 & 0.122 & 0.018 & 0.172 & 0.037 & 0.022 & -0.104 \\
\hline DR-Do you eat your meals at the same time each day & 0.763 & 0.160 & 0.019 & 0.060 & -0.042 & 0.008 & 0.140 \\
\hline DR-Do you eat breakfast at the same time each day & 0.723 & -0.025 & 0.041 & 0.007 & 0.110 & 0.079 & 0.396 \\
\hline DR-Do you sleep at the same time each day & 0.698 & -0.032 & 0.166 & -0.01 & 0.117 & 0.054 & -0.016 \\
\hline $\begin{array}{l}\text { DR-Do you follow a scheduled program for your daily } \\
\text { activities }\end{array}$ & 0.645 & 0.149 & 0.139 & 0.043 & 0.314 & -0.015 & 0.032 \\
\hline DHC-Do you calculate the calories of your meals & 0.101 & 0.694 & -0.186 & 0.007 & 0.168 & 0.066 & -0.242 \\
\hline $\begin{array}{l}\text { DHC-Are you careful about how much food you put on your } \\
\text { plate }\end{array}$ & 0.059 & 0.663 & 0.292 & 0.207 & 0.138 & 0.089 & 0.119 \\
\hline DHC-Do you limit fat in your meals & 0.142 & 0.640 & 0.215 & -0.186 & -0.024 & -0.167 & 0.041 \\
\hline DHA-Do you avoid binge eating when out with friends & -0.017 & 0.203 & 0.718 & 0.093 & 0.034 & -.093 & 0.197 \\
\hline DHA-Do you avoid eating when stressed or disappointed & 0.088 & 0.057 & 0.614 & 0.229 & 0.071 & -0.01 & 0.012 \\
\hline $\begin{array}{l}\text { SMB-Do you concentrate on positive thoughts during } \\
\text { difficulties }\end{array}$ & 0.089 & -0.039 & 0.597 & 0.101 & 0.047 & 0.384 & 0.075 \\
\hline $\begin{array}{l}\text { SMB-Do you empty your brain of thoughts or the next day's } \\
\text { program during bedtime }\end{array}$ & 0.198 & 0.008 & 0.543 & 0.066 & -0.006 & 0.238 & -0.255 \\
\hline DHC-Do you eat organic foods & 0.034 & -0.054 & 0.129 & 0.687 & -0.016 & 0.044 & -0.143 \\
\hline DHA-Do you avoid soft drinks & 0.066 & -0.159 & 0.162 & 0.660 & 0.111 & 0.011 & 0.181 \\
\hline DHA-Do you avoid eating packaged or fast food & 0.100 & 0.123 & 0.286 & 0.598 & 0.069 & -0.081 & 0.160 \\
\hline DHC-Do you check the food labels before buying a product & 0.056 & 0.506 & -0.082 & 0.515 & 0.029 & 0.117 & 0.187 \\
\hline DHC-Do you like cooking & 0.048 & 0.172 & 0.004 & 0.461 & -0.023 & 0.214 & -0.067 \\
\hline PA-Do you exercise in an organized manner & 0.156 & 0.118 & 0.019 & 0.027 & 0.893 & 0.066 & 0.050 \\
\hline
\end{tabular}




\begin{tabular}{|c|c|c|c|c|c|c|c|}
\hline $\begin{array}{l}\text { PA-Do you practice aerobic exercise for } 20 \text { or more } \\
\text { minutes at least } 3 \text { times per week }\end{array}$ & 0.079 & 0.104 & 0.101 & 0.072 & 0.875 & 0.057 & 0.127 \\
\hline $\begin{array}{l}\text { SMB-Do you care about meeting and discussing with your } \\
\text { family on a daily basis }\end{array}$ & 0.003 & 0.123 & 0.162 & 0.034 & -0.099 & 0.736 & -0.007 \\
\hline $\begin{array}{l}\text { SMB-Do you share your personal problems or worries with } \\
\text { others }\end{array}$ & 0.018 & -0.074 & -0.073 & 0.077 & 0.153 & 0.669 & \\
\hline $\begin{array}{l}\text { SMB-Do you balance your time between work, personal life } \\
\text { and leisure }\end{array}$ & 0.286 & -0.073 & 0.205 & 0.113 & 0.196 & 0.467 & -0.219 \\
\hline Routine-Do you eat a good breakfast & 0.422 & -0.001 & 0.028 & 0.033 & 0.264 & 0.082 & 0.635 \\
\hline Routine-Are you careful about not missing a meal each day & 0.524 & -0.057 & 0.051 & 0.061 & 0.033 & 0.159 & 0.528 \\
\hline DHC-Do you eat whole-grain products & 0.068 & 0.414 & 0.118 & 0.105 & 0.046 & -0.009 & 0.425 \\
\hline Eigenvalues & 5.353 & 2.422 & 1.833 & 1.594 & 1.331 & 1.234 & 1.067 \\
\hline$\%$ of Variance & 20.587 & 9.316 & 7.049 & 6.129 & 5.117 & 4.744 & 4.108 \\
\hline Cronbach's alpha & 0.824 & 0.829 & 0.574 & 0.598 & 0.845 & 0.467 & 0.558 \\
\hline
\end{tabular}

Note: $\mathrm{N}=493$, Original subscales: (1) DR=Daily Routine (2) DHA=Dietary Harm Avoidance, (3) DHC=Dietary Healthy Choices, (4) OPE=Organized Physical Activity, and (5) $\mathrm{SMB}=$ Social and Mental Balance. Extraction method: principal component analysis. Rotation method: varimax with kaiser normalization. Eigenvalue $>1$.

Factor 3 favors the principles of mindful eating, and Factor 4 reflects food selection and preparation behaviors that would result in Dietary Harm Avoidance. The practice of mindful eating involves an awareness of the internal cues of hunger and satiety which signals the individual to avoid overconsumption through behaviors which utilize external cues, such as reducing portion sizes and being careful about how much food is on your plate. Contrary to that theme, choosing organic foods, checking food labels and home cooking may be motivated by a desire to avoid pesticides, highly processed foods, and control weight, a trend known as "clean eating" [28-30]. Many RDNs have adopted a whole foods schema and mindful eating principles for purpose of counseling clients on diabetes and weight management, therefore the subscales are theoretically related to each other thus demonstrating good construct validity.

Table 3: Best lifestyle predictors of satisfaction with life.

\begin{tabular}{|l|l|l|l|}
\hline Subscale & Item & $\begin{array}{l}\text { Standardized } \\
\text { Canonical Discriminant } \\
\text { Function Coefficient }\end{array}$ & Correlation Coefficient \\
\hline SMB & $\begin{array}{l}\text { Do you balance your time between work, personal } \\
\text { life and leisure? }\end{array}$ & 0.598 & 0.771 \\
\hline SMB & $\begin{array}{l}\text { Do you concentrate on positive thoughts during } \\
\text { difficulties? }\end{array}$ & 0.354 & 0.578 \\
\hline SMB & $\begin{array}{l}\text { Do you care about meeting and discussing with } \\
\text { your family on a daily basis? }\end{array}$ & 0.318 & 0.506 \\
\hline OPE & $\begin{array}{l}\text { Do you practice aerobic exercise for } 20 \text { or more } \\
\text { minutes at least } 3 \text { times per week? }\end{array}$ & 0.364 & 0.478 \\
\hline $\begin{array}{l}\text { Note: OPE=Organized Physical Exercise, SMB=Social Mental Balance; } 76.3 \% \text { of original cases } \\
\text { predicted satisfaction with life with 4/26 items }\end{array}$
\end{tabular}

The cases were grouped into two categories by the K-Means cluster technique using the life satisfaction items. A discriminant analysis was used to reduce HLPCQ to the most essential response items that predict life satisfaction (Table 3 ). As a result of this procedure the resulting solution identified four HPLCQ items that were able to predict membership in one of two SWL cluster groups resulting in a correct classification $76.3 \%$ of the time. Wilks' Lambda is the proportion of the total variance in the discriminant scores not explained by differences among groups.
The resulting significant Wilks' Lambda of $0.874 \quad(p=0.000)$ indicate that the group means are significantly different. Results of this analysis demonstrate that $75.9 \%$ of cases were correctly classified with the reduced HLPCQ. The relationship between the canonical discriminant function and predictor variables shows a moderate effect between lifestyle and SWL, $r$ $(1,4)=0.355, p=0.000$, explaining $12.6 \%$ of the variation. Zero order correlations with Health Conception-Wellness subscale and life satisfaction items revealed small associations from 0.118 to $0.224, p=0.000$ (Table 4). 
Table 4: SWLS and LHCS-Wellness subscale inter-correlations, means, and standard deviations.

\begin{tabular}{|c|c|c|c|c|c|c|c|c|}
\hline & 1 & 2 & 3 & 4 & 5 & 6 & 7 & 8 \\
\hline $\begin{array}{l}\text { close to my ideal. } \\
\text { clist }\end{array}$ & 1 & & & & & & & \\
\hline $\begin{array}{l}\text { 2. The conditions of my life } \\
\text { are excellent. }\end{array}$ & $0.761^{* *}$ & 1 & & & & & & \\
\hline $\begin{array}{l}\text { 3. I am satisfied with my } \\
\text { life. }\end{array}$ & $0.760^{* *}$ & $0.694^{* *}$ & 1 & & & & & \\
\hline $\begin{array}{l}\text { 4. So far I have gotten the } \\
\text { important things I want in } \\
\text { life. }\end{array}$ & $0.683^{* *}$ & $0.655^{\star *}$ & $0.734^{* *}$ & 1 & & & & \\
\hline $\begin{array}{l}\text { 5. If I could live my life over, } \\
\text { I would change nothing. }\end{array}$ & $0.585^{\star *}$ & $0.504^{* *}$ & $0.575^{\star *}$ & $0.503^{* *}$ & 1 & & & \\
\hline $\begin{array}{l}\text { 6. For me, "being healthy" } \\
\text { is feeling great --on top of } \\
\text { the world. }\end{array}$ & $0.212^{\star *}$ & $0.189^{* *}$ & $0.174^{\star *}$ & $0.126^{\star *}$ & $0.133^{* *}$ & 1 & & \\
\hline $\begin{array}{l}\text { 7. For me, "being healthy" } \\
\text { is actualizing my highest } \\
\text { and best aspirations. }\end{array}$ & $0.224^{\star *}$ & $0.153^{* *}$ & $0.208^{* *}$ & $0.165^{\star *}$ & $0.132^{* *}$ & $0.623^{* *}$ & 1 & \\
\hline $\begin{array}{l}\text { 8. For me, "being healthy" } \\
\text { is when my mind and body } \\
\text { function at their highest } \\
\text { level. }\end{array}$ & $0.120^{\star *}$ & $0.118^{* *}$ & $0.120^{* *}$ & $0.112^{*}$ & 0.071 & $0.397^{* *}$ & $0.500^{* *}$ & 1 \\
\hline M & 5.18 & 5.41 & 5.68 & 5.68 & 4.02 & 4.40 & 4.88 & 4.46 \\
\hline SD & 1.35 & 1.27 & 1.16 & 1.28 & 1.77 & 0.979 & 0.64 & 0.94 \\
\hline
\end{tabular}

As a test of the revised model, the summary index score for the wellness health philosophy variable was entered into a regression analysis along with gender and the best predictors from the HLPCQ scale to evaluate their contributions to satisfaction with life (Table 5). The impact of years of practice was tested, but it did not influence satisfaction with life. Two models were entered to evaluate the contributions of lifestyle and gender to satisfaction with life, and to see whether the wellness health conception influences this outcome. The mean difference between men and women on the life satisfaction index score was $4.14(p=0.002)$. The results of Model 1 were notable because women $(n=472)$ vastly outnumbered men $(n=20)$ in the sample, and as there is very little published on the male dietitian experience, we did not include this as a moderator as a hypothesis. These results suggest that male gender has a significant and negative $(p=0.001)$ effect on life satisfaction which explained $22.5 \%$ of the variance in SWL.

Table 5: Summary of regression analyses predicting satisfaction with life.

\begin{tabular}{|c|c|c|c|c|c|c|}
\hline \multirow{3}{*}{ Gender } & \multicolumn{3}{|c|}{ Model 1} & \multicolumn{3}{|c|}{ Model 2} \\
\hline & B & SE B & $\beta$ & B & SE B & $\boldsymbol{\beta}$ \\
\hline & -0.751 & $0.231^{\star *}$ & -0.129 & -0.626 & $0.229^{*}$ & -0.108 \\
\hline Healthy Lifestyle \& Personal Control Scorea & 0.250 & $0.022^{* *}$ & 0.456 & 0.242 & $0.021^{* *}$ & 0.442 \\
\hline Health Conception Wellness & -- & -- & -- & 0.279 & $0.065^{\star *}$ & 0.171 \\
\hline Adjusted R2 (Full Model) & & 0.225 & & & 0.252 & \\
\hline$F$ for change in $\mathbf{R 2}$ & & $72.296^{\star *}$ & & & $56.167^{* *}$ & \\
\hline
\end{tabular}

The index for the wellness subscale for health conception was added in Model 2 improving the overall model slightly with $25.2 \%$ variance explained. Thus, believing that health and well- being emerges out of the optimal health functioning has a very small positive influence on lifestyle behaviors. The reduced HLPCQ does not include any dietary choice or avoidance items 
due to the small contribution of these responses to between groups variation due to profession of this unique population.

The factor structure of the set of observed variables with confirmatory factor analysis tested the hypothesis that a relationship between these observed variables and their underlying latent constructs exist. The resulting path coefficients demonstrated that there was a small effect for lifestyle on life satisfaction for women $(r=0.27, p<0.000)$ and a moderate effect for our small sample of men $(r=0.694, p<0.000)$ as we described in a previous paper [21]. Although there was shared variance between healthy lifestyle and wellness philosophy, it was small and not significant $(r=0.028, p=0.521)$. Individuals that respond to health risk motivated by health-protection will first consider the severity of the threat and the probability of its occurrence before responding to fear, a negative emotion, that the risk poses [31,32]. The coping response to a risk can be adaptive or maladaptive based on the individual's assessment of the efficacy of the suggested behavior and perceived ability to enact this behavior. The men in our study had a lower mean score on the healthy lifestyle and personal control instrument, but the difference was not significant $(\bar{x}=4.15$ versus $4.60, p=0.086)$. This may have an impact on the choices and methods that a dietitian chooses in their daily practice, but little has been published on the impact of personal control beliefs. Researchers have observed that personal beliefs about the value of the healthrelated behavior and perceived control over a risk are important predictors of a dietitian's likelihood to inform clients on methods to insure food safety when preparing fresh vegetables [33]. Future research should consider personal characteristics of the RDN and her choice of topics and communication of risk to clients.

The degree of fit between lifestyle and career satisfaction of professionals should be evaluated using longitudinal data analytic techniques to confirm the results of this cross-sectional study. Wellness education should begin early in the professional preparation of dietitian-nutritionists, as well as targeted health interventions to promote their wellbeing [34].

The sample of adults in this study was diverse with respect to age, but homogeneous in gender. Life satisfaction has been shown to differ by race, occupational class, and income $[35,36]$. The questionnaire design did not include self-identification with respect to race or ethnicity, and regrettably was not linked to the annual salary survey. Future psychometric studies on dietitians should include race, relationship and marital status, family structure, salary expectations, and general health measures. Ultimately, these efforts would support the physical and social health of dietitians and their clients.

\section{Conclusion}

The aim of this study was to explore the impact of a dietitian's health beliefs, and lifestyle behaviors on satisfaction with life [37]. The most influential factors on the life satisfaction of dietitians were healthy lifestyle and personal control, particularly regular physical activity, work-life balance, and family support. The data provides evidence of a direct negative effect of gender on life satisfaction. The authors did not gather other possible mediating variables, such as stress, earnings, marital status, parenthood or career satisfaction to offer a better explanation for these outcomes.

\section{Funding}

None to declare

\section{Competing and Conflicting Interests}

None to declare

\section{Acknowledgement}

I would like to gratefully and sincerely thank Christina Darviri and associates for the permission to use the HLPCQ questionnaire.

\section{Abbreviations}

Healthy Lifestyle and Personal Control Questionnaire: HLPCQ

Laffrey's Health Conception Scale: LHCS

Registered Dietitian Nutritionist: RDN

Satisfaction With Life: SWL

\section{References}

1. Slawson DL, Fitzgerald N, Morgan KT (2013) Position of the academy of nutrition and dietetics: The role of nutrition in health promotion and chronic disease prevention. J Acad Nutr Diet 113: 972-979.

2. Dalton S (1998) The dietitians' philosophy and practice in multidisciplinary weight management. J Acad Nutr Diet 98: 49-54.

3. Hensel D (2011) Relationships among nurses' professional selfconcept, health, and lifestyles. West J Nurs Res 33: 45-62.

4. Kiy AM (1998) The philosophy of nutrition therapy. Top Clin Nutr 13: 51-62.

5. Fie S, Norman IJ, While AE (2013) The relationship between physicians' and nurses' personal physical activity habits and their health-promotion practice: A systematic review. Health Educ J 72: 102-119.

6. Fredericks SC, Hamilton C (1996) Dietary intakes of registered dietitians. J Am Diet Assoc 96: 25.

7. George V, Fineberg M, Marin V, Rosen A (2016) The Role of registered dietitians in patient education and counseling about physical activity. Top Clin Nutr 31: 190-198.

8. Martin JB, Holcomb JD, Mullen PD (1987) Health promotion and disease prevention beliefs and behaviors of dietetic practitioners. J Am Diet Assoc 87: 609-614.

9. Fraser S, Leveritt M, Ball L (2013) Patients' perceptions of their general practitioner's health and weight influences their perceptions of nutrition and exercise advice received. J Prim Health Care 5: 301-307.

10. Bounds WE (2002) The effects of dietitian weight and selfdisclosure about weight on women's evaluations of registered dietitians. 
11. Ajzen I (2002) Perceived behavioral control, self-efficacy, locus of control, and the theory of planned behavior. J Appl Soc Psychol 32 665-683.

12. Eccles JS, Wigfield A (2002) Motivational beliefs, values, and goals. Annu Rev Psychol 53: 109-132.

13. Segall ME, Wynd CA (1990) Health conception, health locus of control, and power as predictors of smoking behavior change. Am J Health Promot 4: 338-344.

14. Pender NJ (1984) Health promotion and illness prevention. Annu rev Nurse Res 2: 83-105.

15. Pender NJ, Murdaugh CL, Parsons MA (2010) Health promotion in nursing practice.

16. https://www.cdrnet.org/certifications/number-of-registereddietitians-by-state

17. Bosco FA, Aguinis H, Singh K, Field JG, Pierce CA, et al. (2015) Correlational effect size benchmarks. J Appl Psychol 100: 431.

18. Cohen J (1977) Statistical power analysis for the behavioural sciences (Revised edition). New York pp: 7.

19. Hulley SB, Cummings SR, Browner WS, Grady DG, Newman TB, et al. (2013) Designing clinical research. (4th edn) Lippincott Williams \& Wilkins.

20. Lusk SL, Kerr MJ, Baer LM (1995) Psychometric testing of the reduced laffrey health conception scale. Am J Health Promot 9: 220-224.

21. Grace-Farfaglia P, Pickett-Bernard D, White Gorman A, Dehpahlavan J (2017) Health philosophy of dietitians and Its implications for life satisfaction: An exploratory study. Behav Sci 7: 67.

22. Darviri C, Alexopoulos EC, Artemiadis AK (2014) The healthy lifestyle and personal control questionnaire (HLPCQ): A novel tool for assessing self-empowerment through a constellation of daily activities. BMC Public Health 14: 1-10.

23. Diener E, Emmons RA, Larsen RJ, Griffin S (1985) The Satisfaction With Life Scale. J Pers Assess 49: 71-75.

24. Diener E, Inglehart R, Tay L (2013) Theory and validity of life satisfaction scales. Soc Indic Res 112: 497-527.
25. Eid M, Diener E (2004) Global judgments of subjective well-being: Situational variability and long-term stability. Soc Indic Res 65: 245-277.

26. Laffrey SC (1986) Development of a health conception scale. Res Nurs Health 9: 107-113.

27. Laffrey SC (1982) Health behavior choice as related to selfactualization, body weight, and health conception.

28. McCartney M (2016) Margaret McCartney: Clean eating and the cult of healthism. BMJ 354: 4095.

29. Saunders-Hogberg G (2015) Accounting for risks: Identifying water risks in the food and beverage industry using an ecosystem services benchmarking framework (Master's thesis, University of Waterloo). MMR 32: 72.

30. Lofgren IE (2015) Mindful eating: An emerging approach for healthy weight management. Am J Lifestyle Med 9: 212-216.

31. Tanner Jr JF, Hunt JB, Eppright DR (1991) The protection motivation model: A normative model of fear appeals. J Mark 1: 36-45.

32. Rogers RW (1975) A protection motivation theory of fear appeals and attitude change. J Psychol 91: 93-114.

33. Casagrande G, LeJeune J, Belury MA, Medeiros LC (2011) Registered dietitian's personal beliefs and characteristics predict their teaching or intention to teach fresh vegetable food safety. Appetite 56: 469-475.

34. Perdue CN (2016) Emotional intelligence, job satisfaction, and burnout for dietitians (Doctoral dissertation, Walden University).

35. Maher JP, Pincus AL, Ram N, Conroy DE (2015) Daily physical activity and life satisfaction across adulthood. Dev Psychol 51: 1407.

36. Boehm JK, Chen Y, Williams DR, Ryff C, Kubzansky LD, et al. (2015) Unequally distributed psychological assets: Are there social disparities in optimism, life satisfaction, and positive affect? PloS one 10: e0118066.

37. Lacey R, Stafford M, Sacker A, McMunn A (2016) Work-family life courses and subjective wellbeing in the MRC National Survey of Health and Development (the 1946 British birth cohort study). J Popul Ageing 9: 69-89. 